\title{
Postmortem survival characteristics of rat glial cells in culture
}

\author{
PETER G E KENNEDY \\ From the Medical Research Council Neuroimmunology Project, Department of Zoology, University College, \\ London, $U K$
}

SUMMARY Cell-type-specific markers and indirect immunofluorescence were used to determine the longest time interval between death of the animal and removal of tissues that permitted growth in vitro of rat central glial cells. Galactocerebroside ${ }^{+}$oligodendrocytes could not be cultured after more than 1 hour had elapsed, whereas small numbers of glial fibrillary acidic protein (GFAP) ${ }^{+}$ astrocytes and GFAP ${ }^{-}$fibroblastic cells could still be cultured for as long as 6-7 hours after death. These observations may reflect a greater susceptibility of oligodendrocytes to anoxia compared with astrocytes and fibroblasts.

In tissue culture experiments using tissues of nervous system origin it is common practice to kill animals individually rather than in batches prior to culture. This is generally assumed to be sensible because of the likely effects of anoxia on tissues with consequent reduction of the quality of the cultures which may result if large numbers of cadavers are left for prolonged periods on the laboratory bench before dissection. Moreover, it seems logical to assume that different cell types would vary in the extent to which they can withstand anoxia and, therefore, that the cellular composition of cultures would vary following different periods after death. To test these possibilities cell-type-specific markers and indirect immunofluorescence were used in this study to determine how long different neonatal rat brain glial cell types survive following death, survival being defined by the ability of these various cell types to grow in tissue culture.

\section{Methods}

The techniques used in the study have been previously described in detail. ${ }^{1-3}$ All experiments were performed on 6 day old Wistar rats. The animals were killed by decapitation

Present address and address for reprint requests: Department of Neurology, Institute of Neurological Sciences, Southern General Hospital. 1345 Govan Road, Glasgow G51 4TF, Scotland, UK.

Received 23 September 1986.

Accepted 23 October 1986 and the heads were left at room temperature for periods ranging from $0-15$ hours $(0,1,2,3,4,5,6,7,8$ and 15 hours prior to dissection). These experiments were performed on three separate occasions and the brains of two animals were used for each time point. The corpus callosum was dissected aseptically and put into tissue culture as previously described. ${ }^{13}$ In brief, corpus callosum tissue from each pair of animals was placed in MEM-HEPES, chopped into small pieces with scissors and digested for one and a half hours at $37^{\circ} \mathrm{C}$ in $0.125 \%$ trypsin and $0.02 \%$ collagenase. The cells were then dissociated by repeated trituration through a Pasteur pipette and the resulting cell suspension was plated on $13 \mathrm{~mm}$ glass coverslips (20,000 cells per coverslip) in Dulbecco's Modified Eagle's Medium containing $10 \%$ foetal calf serum in Linbro Multiwell plates. The cells were grown in a humidified atmosphere of $90 \%$ air: $10 \% \mathrm{CO}_{2}$ at $37^{\circ} \mathrm{C}$ and the medium changed every 2 days. Cells were studied after 5-7 days in culture.

Cell identification in these cultures was carried out using indirect immunofluorescence and cell-type-specific markers as previously described. ${ }^{12}$ Astrocytes were identified by using a rabbit antiserum against glial fibrillary acidic protein (GFAP) $^{14}$ (rabbit anti-GFAP, diluted 1:100), oligodendrocytes using a rabbit antiserum directed against galactocerobroside ${ }^{2}$ (rabbit anti-GC, diluted 1:40), and fibroblasts by mouse monoclonal antibodies to Thy $1 \cdot 1^{1}$ (mouse anti-Thy-1/1). Antibody binding was visualised with goat anti-rabbit IgG conjugated to rhodamine (G anti-RIgRd, Nordic) or goat anti-mouse IgG conjugated to fluorescein (G anti-MIg-Fl, Nordic). Immunofluorescence assays were performed as previously described. ${ }^{13}$ Cells growing on glass coverslips were incubated with the primary antibody for 25 minutes at room temperature, washed and 
Table In vitro survival of neonatal rat central glial cells following death of the animal

\begin{tabular}{llll}
\hline $\begin{array}{l}\text { Hours } \\
\text { following } \\
\text { death }\end{array}$ & $\begin{array}{l}\text { GC }^{+} \\
\text {oligodendrocytes* }\end{array}$ & $\begin{array}{l}\text { GFAP } \\
\text { astrocytes }\end{array}$ & $\begin{array}{l}\text { GFAP } \\
\text { fibroblastic } \\
\text { cells }\end{array}$ \\
\hline 0 & + & + & + \\
1 & + & + & + \\
2 & - & \pm & \pm \\
3 & - & \pm & \pm \\
4 & - & \pm & \pm \\
5 & - & \pm & \pm \\
6 & - & - & \pm \\
7 & - & - & - \\
8 & - & - & - \\
15 & - & \pm & \pm \\
\hline
\end{tabular}

*Cell growth was assessed on a simple arbitrary scale:

+ denotes good growth of cells with cultures containing approximately $5 \% \mathrm{GC}^{+}$oligodendrocytes, $40 \% \mathrm{GFAP}^{+}$astrocytes and $50 \%$ GFAP- fibroblastic cells. At 0-1 hours the total number of cells per coverslip was more than 5,000 cells after 5 days in culture.

\pm denotes sparse cell growth. At and after 2 hours the total number of cells per coverslip was usually less than 200 after 5 days in culture.

- denotes absence of any cell growth.

then incubated with either $\mathbf{G}$ anti-RIg-Rd or $\mathbf{G}$ anti-MIg-Fl for 25 minutes at room temperature. After washing the cells were fixed in acid-alcohol $(95 \%$ ethanol: $5 \%$ glacial acetic acid) at $-20^{\circ} \mathrm{C}$ for 10 minutes, washed and mounted in glycerol on glass slides. The cells were then examined under a Zeiss Universal fluorescence microscope equipped with epiillumination and phase contrast optics. At least 200 cells per coverslip were counted. For staining with GFAP the cells were prefixed in acid-alcohol prior to staining.

\section{Results}

The results of these experiments are summarised semi-quantitatively in the table. In cultures obtained from tissues at 0 hours and 1 hour after death, $5 \%$ of the cells were $\mathrm{GC}^{+}$(positive) oligodendrocytes, $40 \%$ were $\mathrm{GFAP}^{+}$astrocytes and $50 \%$ were $\mathrm{GFAP}^{-}$ (negative) Thy $1^{+}$fibroblasts, consistent with previous detailed studies. ${ }^{13}$ There was no difference in the quality of the cultures or the proportions of the various cell types at 0 and 1 hours, and the total number of cells per coverslip was 5,000 or more at both these time periods. After the rat heads had been left for 2 hours at room temperature it was no longer possible to culture $\mathrm{GC}^{+}$oligodendrocytes and only small numbers of GFAP $^{+}$cells or GFAP ${ }^{-}$fibroblastic cells were detected, the total number of cells per coverslip seldom exceeding 200 . This pattern of sparse cell survival continued to be observed until 7 hours after death when it was no longer possible to grow GFAP ${ }^{+}$ cells although a few GFAP- fibroblastic cells could still be cultured. By 8 hours following death it was not possible to grow any neural cell types in culture.

\section{Discussion}

These experiments show a differential survival pattern of rat brain glial cells in culture following death of the animal. No $\mathrm{GC}^{+}$oligodendrocytes could be grown after more than 1 hour had elapsed after death, whereas both GFAP $^{+}$astrocytes and GFAP $^{-}$ fibroblasts could be grown in culture after as long as 6 or 7 hours after death. All of the cell cultures obtained after 2 hours contained far fewer cells compared with the cultures prepared at early time intervals. These differences in survival times may well reflect different sensitivities of these cells to anoxia; oligodendrocytes appeared to withstand anoxia much less well than did astrocytes and fibroblasts. An additional factor in the poor survival of oligodendrocytes after 1 hour is that the viability of these cells in culture may be critically dependent on the numbers of other cell types present such as astrocytes and fibroblasts, which were also considerably reduced after this time.

These observations may be of particular relevance to human cell cultures where conflicting results have been obtained. In previous studies ${ }^{5-7}$ success in preparing neural cell types from aborted human fetuses varied according to the source of the material. In the case of vacuum-extracted fetuses, which were almost always cultured within 2 hours of death, the success rate was very high (more than $90 \%$ ). On the other hand, prostaglandin-induced fetal material, which may well have died several hours before delivery, could only be grown in culture in about $40 \%$ of cases. In the latter case it is possible that the relatively few successful cultures had been prepared from fetuses which had died within 2 hours of delivery. Moreover, even in "unsuccessful" human cultures, a very small number of $\mathrm{GFAP}^{+}$astrocytes and $\mathrm{GFAP}^{-}$ fibroblastic cells could be grown in culture even when $\mathrm{GC}^{+}$oligodendrocytes could not be grown, ${ }^{6}$ providing further evidence of the greater susceptibility of oligodendrocytes to anoxia.

Lewis and $\mathrm{McCoy}^{8}$ used histological methods to determine the periods of survival of several different types of cell from a variety of rat tissues after death. The criterion for survival was the presence of intracellular granules and vacuoles which had an affinity for neutral red; when the tissues died the granules and vacuoles ceased to be labelled with this dye which then diffused throughout the cell. Using this method it was found that although some tissues such as kidney epithelium and smooth muscle survived for up to ten days after the death of the animal, nerve cells from the cerebral cortex and cerebellum only survived for 1 hour. Alvarez ${ }^{9}$ reported that the survival rates after death of a variety of tissues could be extended by refrigeration at $0^{\circ} \mathrm{C}$ prior to culture. Murray and Stout ${ }^{10}$ confirmed this study for neural tissues by showing that after storing sympathetic ganglia at $4^{\circ} \mathrm{C}$ many hours after the latter had been removed from patients at operation it was still possible to culture 
human peripheral neurons. In addition it has been claimed that by keeping tissues refrigerated at $6^{\circ} \mathrm{C}^{11}$ it was possible to grow human fetal neural cells in culture up to 9 days after the nervous tissue had been removed from the fetuses. However, the various neural cell types in these experiments were not positively identified with specific antisera. In limited experiments using human fetal tissues it was possible to obtain reasonably good cell cultures of astrocytes, oligodendrocytes, fibroblasts, peripheral neurons and Schwann cells from vacuum-extracted dorsal root ganglia and spinal cord tissues after they had been stored overnight at $4^{\circ} \mathrm{C}$ in buffered medium (MEMHEPES). ${ }^{6}$

The main practical implication of the experiments described here with neonatal corpus callosum cultures is that when large numbers of animals are being killed for the preparation of nervous system tissue cultures, they should be killed individually prior to dissection and not killed in batches and left at room temperature for prolonged periods of time. If there are to be delays in dissection once the animals have been killed then it seems sensible to store the cadavers at $4^{\circ} \mathrm{C}$. Moreover, tissue culture work is now being widely used in both experimental and clinical research. For example, biopsy material is being studied from human brain tumours and benign brain lesions. ${ }^{12}$ The results reported above may have relevance to these studies in that the pattern of cell survival in cultures derived from these sources may be directly affected by the time interval between obtaining tissues and cooling or establishment of cultures.

I thank Professor Martin Raff for his support and helpful discussions. I am also grateful to Drs F Schon, D I Graham and G B Clements for helpful discussions. This work was supported by the National Fund for Research into Crippling Diseases.
References

1 Raff MC, Fields KL, Hakomori S, et al. Cell-typespecific markers for distinguishing and studying neurons and the major classes of glial cells in culture. Brain Res 1979;174:283-308.

2 Raff MC, Mirsky R, Fields KL, et al. Galactocerebroside is a specific cell surface antigenic marker for oligodendrocytes in culture. Nature 1978;274: 813-6.

3 Kennedy PGE, Lisak RP. A search for antibodies against glial cells in the serum and cerebrospinal fluid of patients with multiple sclerosis and Guillain-Barre syndrome. J Neurol Sci 1979;44:125-33.

4 Eng LP, Vanderhaeghen JJ, Bignami A, Gerstl B. An acidic protein isolated from fibrous astrocytes. Brain Res 1971;28:351-4.

5 Kennedy PGE, Lisak RP, Raff MC. Cell-type-specific markers for human glial and neuronal cells in culture. Lab Invest 1980;43:342-51.

6 Kennedy PGE. A study of cell-type-specific markers in neural cell cultures and their application to the study of demyelinating diseases. PhD thesis. University of London, 1980.

7 Kennedy PGE, Fok-Seang J. Studies on the development, antigenic phenotype and function of human glial cells in tissue culture. Brain 1986;109:1261-77.

8 Lewis WH, McCoy CC. The survival of cells after the death of the organism. Bull Johns Hopkins Hosp 1922;33:284-93.

9 Alvarez WC. The survival of tissues after the death of an animal. $Q$ Rev Biol 1937;12:152-64.

10 Murray MR, Stout AP. Adult human sympathetic ganglion cells cultivated in vitro. Am J Anat 1974;80: 225-73.

11 Hogue MJ. Brain cells from human fetuses and infants, cultured in vitro after death of the individuals. Anat $\operatorname{Rec}$ 1950;108:457-75.

12 Morgan D, Freshney RK, Darling JL, Thomas DGT, Celik R. Assay of anti-cancer drugs in tissue culture: cell cultures of biopsies from human astrocytoma. $\mathrm{Br} J$ Cancer 1983;47:205-14. 